\section{Eduardo Becerra}

Profesor titular de Literatura Hispanoamericana de la Universidad Autónoma de Madrid y profesor invitado en las universidades de Estudios Extranjeros de Pekín, New York University en Madrid, Middlebury College en Madrid, Universidad de Almería y Carleton University (Ottawa-Canadá). Es autor de los libros Rubén Darío y su obra (2000) y Pensar el lenguaje; escribir la escritura (experiencias de la narrativa hispanoamericana contemporánea) (1995); y coautor, junto con Teodosio Fernández y Selena Millares, del manual Historia de la literatura hispanoamericana (1995). Asimismo, ha sido editor de los libros Desafíos de la ficción (Cuadernos de América sin Nombre, Universidad de Alicante, 2002), Farabeuf, de Salvador Elizondo, Editorial Cátedra, 2000; Líneas aéreas (guía de la nueva narrativa hispanoamericana), Editorial Lengua de Trapo, 1999, Poemas escogidos, de Rubén Darío, Editorial McGraw-Hill, 1997, y Las lanzas coloradas, de Arturo Uslar Pietri, Editorial Anaya \& Muchnik, 1995. En sus artículos y conferencias ha abordado la obra de autores como Mario Benedetti, Juan Rulfo, Jorge Luis Borges, Julio Cortázar, Mario Vargas Llosa, Severo Sarduy, Ricardo Piglia, Mayra Montero, Héctor Abad Faciolince, entre otros, y temas como el cuento hispanoamericano, la poesía uruguaya del siglo $\mathrm{XX}$, el $98 \mathrm{y}$ el ensayo hispanoamericano, la novela cubana del exilio y la narrativa hispanoamericana actual y su recepción en España.

1

Saúl Sosnowski, "Cartografía y crítica de las letras americanas», introducción a Lectura crítica de la literatura americana, Caracas, Ayacucho, 1996 (4 vols.), vol. I, págs. IX-LXXXVIII.

\section{2}

Roberto Fernández Retamar, Para una teoría de la literatura hispanoamericana y otras aproximaciones, La Habana, Casa de las Américas, 1975.
Hacia la descolonización de la colonia. Testimonio, crítica literaria y tradición ancilar latinoamericana

EDUARDO BECERRA

\title{
HACIA LA DESCOLONIZACIÓN DE LA COLONIA. TESTIMONIO, CRÍTICA LITERARIA Y TRADICIÓN ANCILAR LATINOAMERICANA
}

\author{
EDUARDO BECERRA
}

Aunque el título de este encuentro nos invita a rastrear presencias de los periodos precolombino y colonial en la literatura hispanoamericana posterior, me he permitido recorrer un camino en cierto modo inverso: trataré de señalar cómo algunas circunstancias que se produjeron en el campo de la literatura y la crítica hispanoamericanas, digamos que entre los años setenta y noventa, abrieron la puerta a una mirada retrospectiva sobre esta tradición literaria, lo que tendría consecuencias muy significativas en el campo de los estudios literarios coloniales (entre otros). Este proceso ha implicado a un buen número de actores y de fenómenos y sus efectos han sido de gran complejidad y diversidad; digo esto para adelantar desde el comienzo que el panorama que ofreceré a continuación será muy general y por ello irremediablemente modesto y esquemático.

En el prólogo de 1996 a los cuatro volúmenes recopilatorios de artículos críticos publicados por la Biblioteca Ayacucho bajo el título de Lectura crítica de la literatura americana ${ }^{1}$, Saúl Sosnowski señalaba que, si hubiera que establecer un punto de partida de las transformaciones operadas en los últimos tiempos en el campo de la crítica, este habría de situarse en los años sesenta, momento en el que la revolución cubana provoca una politización de la actividad crítica que, entre otros efectos, llevará a una profunda revisión del canon. Un poco más adelante, al destacar dos acontecimientos especialmente relevantes dentro de este campo en las últimas décadas, Sosnowski defiende, por un lado, el papel crucial jugado por la producción y la recepción de la literatura testimonial y, por otro, subraya la importancia adquirida por los estudios coloniales y el rastreo de su estamento fundacional dentro de la tradición hispanoamericana. Aunque el autor no vincule directamente ambas parcelas, mi intención en lo que sigue será mostrar las relaciones que guardan tales propuestas.

Un buen punto de partida para empezar a dibujar este cauce pueden ser algunos de los artículos que escribe Roberto Fernández Retamar en la década de los setenta, luego recogidos en su volumen Para una teoría de la literatura hispanoamericana ${ }^{2}$. Si en el trabajo del mismo título, de 1972, destaca la condición neocolonial de toda tentativa por establecer un valor universal de la crítica y teoría literarias, tres años después, en el artículo «Algunos problemas teóricos de la literatura hispanoamericana», señalará la tradición ancilar como la verdadera línea central de la literatura de Hispanoamérica (y recurre para demostrarlo a los ejemplos de las crónicas, el ensayo y a discursos y géneros como la poesía conversacional). El libro de Retamar encarna una tentativa por, según sus propias palabras, lograr una imprescindible descolonización de la crítica que ha de pasar por su politización; y en este último punto surge el testimonio como uno 
de los buques insignia de estas propuestas, ya que constituye un signo central de la literatura revolucionaria cubana. Descolonización, a través de la defensa de una teoría conscientemente regional, y politización, mediante la recuperación de la autoconsciencia del carácter ancilar de la tradición de la que emerge esta literatura, se proponen así, según Retamar, como las nuevas pautas a seguir para la consecución de una expresión específicamente hispanoamericana también en el campo de la crítica literaria.

La irrupción y el auge de la escritura-testimonio podría haberse considerado como otro capítulo, más o menos significativo, en la historia literaria de Hispanoamérica. Pero su recepción crítica de inmediato condujo a otro tipo de planteamientos, digamos que más radicales. Esto se aprecia muy pronto, en 1978, en El cambio en la noción de literatura, de Carlos Rincón $n^{3}$, que institucionaliza ya en la crítica hispanoamericanista una serie de lugares que vienen de los planteamientos de Fernández Retamar y que serán motivos recurrentes en discusiones posteriores. Rincón reitera el papel transgresor del género testimonial y subraya su importancia como espacio textual que invita al replanteamiento de la tradición latinoamericana y que al tiempo evidencia la necesidad de un cambio de paradigma en los análisis literarios. Un cambio que tiene que ver con el abandono de la concepción esencialista e inmanentista de la literatura, otorgada por la ideología burguesa de la modernidad, con el fin de incorporar el análisis de los procesos sociales como parte del ejercicio crítico. No se trata de volver a una sociología de la literatura al uso sino de reubicar los discursos literarios en el espectro general de los discursos sociales y culturales en su conjunto, sin ningún privilegio ni jerarquía. Para el crítico colombiano, las formas narrativas documentales son las que mejor dan respuesta a esta nueva situación y el testimonio surge así nuevamente como paradigma al concretar en su discurso una poética estrechamente vinculada con determinada praxis política.

Este libro insinúa ya las transformaciones que van a expresarse de manera más contundente a partir de la década de los ochenta respecto a la necesidad de una nueva manera de abordar los estudios literarios (si es que aún puede utilizarse tal adjetivo a estas alturas).
Las propuestas de Rincón implican el sacar a la literatura de la esfera de la representación y mediación simbólica para reintroducirla en la esfera de las prácticas sociales. El testimonio vuelve a surgir así como discurso ejemplar sobre todo frente a esa apoteosis de lo literario que encarnarían las obras de la llamada nueva novela de los sesenta o narrativa del boom. En esta línea se inscriben las opiniones de Miguel Barnet en sus trabajos tempranos, que trataron de elaborar una de las primeras poéticas del género, como «La novela-testimonio: socioliteratura $»^{4}$, donde carga contra la nueva novela y su emblema más conocido, el realismo mágico, y donde además titula uno de sus apartados con una pregunta muy reveladora del problema que venimos tratando: « $\dot{i}$ Muerte de la ficción?» En esta pregunta se concitan los aspectos clave de la consagración del testimonio en el campo de la crítica y de la posibilidad de encontrar una vía de reinterpretación y recuperación de la literatura colonial desde nuevas perspectivas, como veremos un poco más adelante.

Cuando, en los ochenta, comienza el auge de los estudios sobre este género, en la mayor parte de los casos se insiste en lo que el testimonio supone de ruptura con las convenciones básicas de lo literario y en la relación directa de su discurso con la verdad. No hay tiempo para entrar en los debates y matizaciones que ha provocado esta caracterización. Me interesa a estas alturas simplemente resaltar esa vinculación y los caminos que abre en el terreno de cierta crítica hispanoamericanista. Si atendemos, por ejemplo, a la recopilación editada por René Jara y Hernán Vidal en 1986, Testimonio y literatura ${ }^{5}$, se aprecia de inmediato lo que vengo diciendo. Ya en el prólogo, René Jara nos habla de cómo en el discurso testimonial encontramos la huella de lo real antes que su representación, y, en idéntico sentido, Renato Prada Oropeza en otro artículo insiste en la consideración de la enunciación testimonial como acto, afirmación que entronca con las conocidas reflexiones de Margaret Randall en las que defiende la narrativa testimonial como acción carente de cualquier tipo de ambición teórica, o de $\mathrm{Hu}$ go Achugar cuando defiende su función prag-
3

Carlos Rincón, El cambio en la noción de literatura, Bogotá, Instituto Colombiano de Cultura, 1978.

4

Miguel Barnet, "La novela-testimonio: socioliteratura», en La fuente viva, La Habana, Letras Cubanas, 1983, págs. 12-42.

5

René Jara y Hernán Vidal (eds.), Testimonio y literatura, Institute for the Study of Ideologies and Literature, Minneapolis, 1986.

Hacia la descolonización de la colonia. Testimonio, crítica literaria y tradición ancilar latinoamericana 
Renato Prada Oropeza, «De lo testimonial al testimonio. Notas para un deslinde del discursotestimonio", en René Jara y Hernán Vidal, ob. cit.; Margaret Randall, "¿Qué es y cómo se hace un testimonio?», en John Beverley, y Hugo Achugar (eds.), La voz del otro: Testimonio, subalternidad y verdad narrativa. Lima -Pittsburgh: Latinoamericana Editores, 1992; Hugo Achugar, «Literatura / literaturas y la nueva producción literaria latinoamericana», Revista de Crítica Literaria Latinoamericana, 15, 29, 1989, págs. 153-165.

\section{7}

John Beverley, «Anatomía del testimonio", Revista de Crítica Literaria Latinoamericana, 13-25, 1987, págs. 7-16 (pág. 15).

8

John Beverley, "Post-Literatura», Nuevo Texto Crítico, 7, 14-15, 1994-1995, págs. 385-400 (pág. 398).

9

Walter Mignolo, en «La lengua, la letra, el territorio (o la crisis de los estudios literarios coloniales)» en Saúl Sosnowski (comp.), op. cit., págs. 3-29.

Hacia la descolonización de la colonia. Testimonio, crítica literaria y tradición ancilar latinoamericana EDUARDO BECERRA mática ejemplarizante ${ }^{6}$, o de John Beverley cuando insiste en su condición extraliteraria y en la necesidad de mantenerlo fuera de los circuitos de la cultura letrada, puesto que el género testimonial «pone en tela de juicio la institución históricamente dada de la literatura como un aparato de dominación y enajenación. El deseo y la posibilidad de producir testimonios, la creciente popularidad del género quieren decir que hay experiencias vitales en el mundo hoy que no pueden ser representadas adecuadamente en las formas tradicionales de la literatura burguesa, que en cierto modo serían traicionadas por éstas» ${ }^{7}$.

Así, uno de los valores fundamentales del testimonio vendrá dado por esta exigencia de salirse fuera de la literatura (categoría que a estas alturas aparece marcada por su origen burgués y, añadiría, eurocéntrico y por ello neocolonial). En otro de sus artículos, Beverley insiste en esta idea al señalar cómo el testimonio nos invita a entrar al territorio de lo que él mismo define ya en los años noventa como post-literatura, idea que «sugiere no tanto la superación de la literatura como forma cultural sino una actitud más agnóstica ante ella. Como he señalado en otras ocasiones -continúa-, una de las lecciones que ofrece el testimonio es que hace falta leer hoy día no sólo "a contrapelo" como en la práctica de la deconstrucción académica, sino contra la literatura misma»8.

Recopilando algunas de las ideas que se han ido exponiendo, este nuevo campo de juego crítico (que no es por supuesto el único) afirma asumir una postura descolonizadora, de marcado sesgo ideológico, y que parte de una idea de literatura considerada como una imposición colonial con la que es imprescindible romper. La sustitución de la noción de literatura por la de discurso, ya no marcado estéticamente ni implicado en una labor de representación o mediación simbólica, se asume como necesidad ineludible. Al lado de todo ello, la recuperación de la idea de tradición hispanoamericana como tradición eminentemente ancilar acaba de apuntalar estos nuevos paradigmas. Lo más importante en estas nuevas posiciones digamos que "post-literarias» está en las posibilidades que ofrecen de reelaborar la propia tradición, incorporando nuevos materiales antes eludidos y atenuando la representatividad de muchos de los hitos de la literatura hispanoamericana canonizados por esa misma tradición. Por supuesto, la muy vigente discusión sobre el canon se encuentra en la trastienda de estos planteamientos, y a ella habrá que referirse.

Esta labor reinterpretativa, unida a la intención descolonizadora que la anima, se viene aplicando a parcelas muy diversas de la cultura de Hispanoamérica; no obstante, parece lógico que uno de los objetivos fundamentales que se plantee sea el de «descolonizar» aquellas épocas donde la producción cultural se encuentra más marcada por una situación de dependencia. La colonia surge así como un periodo ahora lleno de posibilidades y se cuestionan algunas propuestas (entre las que se encuentra, paradójicamente, la del propio Fernández Retamar) que proponían la exclusión del periodo colonial del campo de la tradición hispanoamericana por ese contexto de dependencia desde el que surge. A partir de aquí, y a la hora de exponer las consecuencias de estos planteamientos en la recuperación y auge de los estudios coloniales desde nuevas perspectivas, no es fácil trazar un recorrido nítido del proceso, sólo trataré de mostrar algunas equivalencias que considero muy reveladoras.

Considero algo más que una casualidad que más o menos por las mismas fechas, la década de los ochenta, en que se consolidan estos postulados comience una recuperación crítica del periodo colonial desde nuevas posiciones. La vinculación directa entre tales procesos puede apreciarse en el artículo de Walter Mignolo «La lengua, la letra, el territorio (o la crisis de los estudios literarios coloniales)»9 , de 1986, que comienza destacando la toma de conciencia de la complejidad cultural de la colonia manifestada en una serie de estudios que comienzan a publicarse en esa década y que se sustentan en la recuperación de discursos sin valor estético previo con los que se pueden así superar «las restricciones impuestas por la noción de literatura». Son los mismos años en los que comienzan a aparecer las tesis de Mabel Moraña y John Beverley sobre el barroco y las de Rolena Adorno sobre las nuevas perspectivas en los estudios coloniales y sobre el sujeto social criollo. En todos estos análisis el punto de partida supone la puesta en marcha de nuevos paradigmas inscritos en el proceso que venimos analizando. Así, Rolena Adorno comienza su conocido artículo «Nuevas perspectivas en los estudios 
coloniales latinoamericanos» resaltando la necesidad de partir de la sustitución de la noción de literatura por la de discurso, con el fin de desligar los análisis del rango europeo o eurocéntrico de lo literario para abrirlos al dominio de la palabra y las voces no escuchadas que el discurso permite oír. Mabel Moraña, por su parte, reivindicará en su relectura del barroco la obligación de atender a la dinámica socio-cultural de la colonia a la hora de establecer las singularidades del barroco de ultramar, línea seguida también por John Beverley en su artículo «Nuevas vacilaciones sobre el barroco» ${ }^{10}$. En todos los casos, el objetivo es desligar la cultura colonial de la sombra de la metrópoli y rastrear aquellas presencias en las que es posible detectar una alteridad respecto a la hegemonía imperial capaz de trasladar el dilema de la identidad hispanoamericana a tiempos anteriores a la independencia. La colonia es así recuperada como un tiempo donde ya pueden rastrearse discursos de origen e identidad, para ello, sin embargo, es necesario que la literatura pase un tanto a un segundo plano, pues constituye en esa época un espacio de producción discursiva fuertemente controlado por los mecanismos de poder y hegemonía de esa ciudad letrada perfectamente dibujada por Ángel Rama.

El resultado inmediato es el de la ampliación del canon colonial (entre otros), en la forma en que lo propone, por ejemplo, Walter Mignolo en su artículo «Entre el canon y el corpus. Alternativas para los estudios literarios en y sobre América Latina». Mignolo propone la sustitución de la noción de canon («concebido en términos de estructuras simbólicas de poder y de hegemonía») por la de corpus («concebido en términos de estructuras simbólicas tanto de poder y hegemonía como de oposición y resistencia a través del espacio social») como objeto de estudio de la crítica. «De esta manera -continúa Mignoloel campo de los estudios literarios se concibe más como un corpus heterogéneo de prácticas discursivas y artefactos culturales. El hecho de que alguna de ellas o de ellos adquiere estatuto canónico es parte de la complejidad de fuerzas sociales en conflicto pero de ninguna manera un fenómeno que naturalmente define el campo de estudio y determina lo que es necesario celebrar. Habría muchos otros aspectos que destacar, entre ellos la fuerte presencia de la escritura femenina, las tradiciones orales y los productos culturales híbridos de la colonia; todos los cuales ayudan a comprender la fuerza de un corpus que, en los estudios literarios, había quedado oculto por una noción de literatura que identificaba el canon con el campo de estudios y que tenía en las historias de la literatura la expresión de su autoridad» ${ }^{11}$. Esta larga cita expone los argumentos e implicaciones fundamentales de las nuevas propuestas y la posibilidad de su aplicación a un mundo colonial que deja de ser un espacio homogéneo, tal y como quiere ser reflejado por la autoridad que emana del canon, para convertirse en un ámbito lleno de fuerzas en pugna visibles en la fisonomía plural y antijerárquica del corpus.

No hay mucho tiempo ni espacio para hacer valoraciones exhaustivas y complejas de toda esta problemática. Una primera conclusión evidente es que desde tales presupuestos el análisis de la tradición hispanoamericana se enriquece al incorporar nuevos referentes y le dota de una mayor complejidad al tratar de esquivar posibles reduccionismos. Sólo por esta razón estos ejercicios críticos merecen ser atendidos y considerados. Ello, sin embargo, no evita que, llevados al exceso, planteen problemas que en muchos casos son los mismos que aquellos que manifiestan querer eludir. Saúl Sosnowski, en el trabajo que citábamos al comienzo, advertía del peligro de sustituir un paradigma por otro, lo que convertiría a un proyecto que pretende ampliar y enriquecer la visión de lo literario en un ejercicio igualmente reductor e incluso autoritario. Algo de esto se percibe en algunas de las reflexiones de Mignolo en este último artículo. En determinado momento, al comentar el libro de Serge Gruzinski La colonization de l'imaginaire. Sociétés indigènes et occidentalisation dans le Mexique espagnol XVI-XVII siècle (1988), señala: "Géneros discursivos no canónicos tienen un lugar fundamental en este libro. Las relaciones geográficas, los títulos primordiales, testamentos y litigios de tierra despliegan un panorama de prácticas discursivas a través de fronteras culturales en los que se entrecruzan aspectos de colonización, de dominación, de resistencia que habían quedado ocultos al literaturólogo encandilado por las batallas de Ercilla, las delicias de Balbuena y las tretas de Sor Juana»12. El que nos encadilen las batallas de Ercilla no ha de llevarnos necesariamente a cerrar los ojos al
10

Rolena Adorno, «Nuevas perspectivas en los estudios coloniales latinoamericanos», Revista de Crítica Literaria Latinoamericana, 14, 28, 1988, págs. 11-28; «El sujeto colonial y la construcción cultural de la alteridad», $R e-$ vista de Crítica Literaria Latinoamericana, 14, 28, 1988, págs. 55-68; Mabel Moraña, «Barroco y conciencia criolla en Hispanoamérica», Revista de Critica Literaria Latinoamericana, 14, 28, 1988, págs. 229-251; «Para una relectura del barroco hispanoamericano: problemas críticos e historiográficos», Revista de Crítica Literaria Latinoamericana, 15, 29, 1989, págs. 219231; John Beverley, «Nuevas vacilaciones sobre el barroco", Revista de Crítica Literaria Latinoamericana, 14, 28, 1988, págs. 215-227.

11

Walter Mignolo, «Entre el canon y el corpus. Alternativas para los estudios literarios y culturales en y sobre América Latina», Nuevo Texto Crítico, 2, 14-15, 19941995, págs. 23-36 (pág. 25).

12

Ibidem, pág. 30.

Hacia la descolonización de la colonia. Testimonio, crítica literaria y tradición ancilar latinoamericana EDUARDO BECERRA 


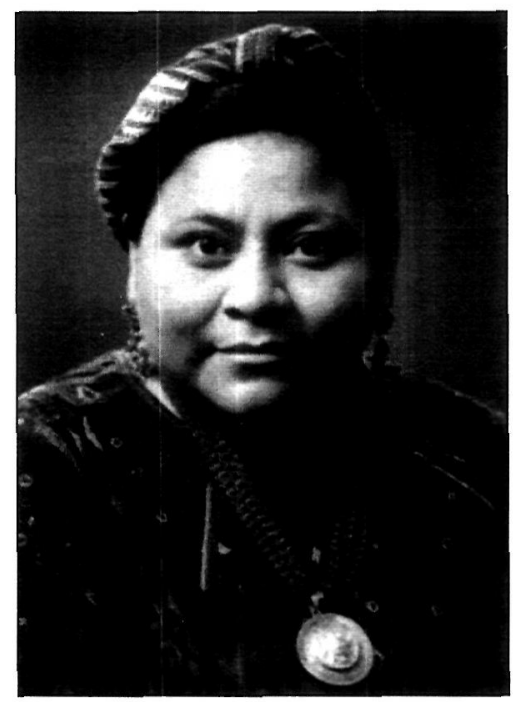

Rigoberta Menchú. sentido imperialista que se desprende de su por otra parte extraordinario poema épico; tampoco la fascinación por la poesía de Sor Juana tiene por qué provocarnos un estadio hipnótico capaz de hacernos olvidar que, por ejemplo, su tratamiento del mito de Faetón nos pone en contacto también con «esos aspectos de colonización, de dominación y de resistencia» mencionados por Mignolo. Las palabras del críti$\mathrm{co}$, y las ideas generales que expone en su artículo, más que fomentar, como defiende en el mismo texto, el diálogo entre críticos literarios y antropólogos, etnohistoriadores e historiadores del arte, parecen privilegiar el hecho de que sean esas otras áreas de estudio las que mejor contribuyen al conocimiento de las culturas y parecen invitar también a la autoinmolación del crítico literario. El riesgo está en una posición demasiado exclusivista dentro de esa post-literatura de la que hablaba Beverley para, desde ella, más que invocar la cooperación de otras esferas culturales, se pretenda borrar casi por completo la presencia de lo literario.

La tentativa por descolonizar la producción colonial, sin que deba ser rechazada de antemano, no debe obviar la realidad de una cultura dependiente en muchos sectores de su producción literaria (lo que no la convierte de inmediato y sin más en mero reflejo de la literatura metropolitana) y en la que el peso de la ciudad letrada y de los mecanismos de control ideológico de los centros de poder fue incontestable. Eludir esta realidad supone tener que rastrear en discursos que operan fuera de enormes áreas de la producción literaria colonial, lo cual no deja de plantear problemas de diverso signo. Además, en ocasiones puede distorsionar la visión de las propias obras literarias al abordar su análisis desde presupuestos ideológicamente muy condicionados de partida. Sólo tengo espacio para dar un ejemplo muy concreto que, en mi opinión, ilustra este problema y refleja también algunos efectos de la aplicación de los nuevos paradigmas de la crítica que he venido analizando a los textos de la colonia.

Dentro del muy debatido problema de la

Hacia la descolonización de la colonia. Testimonio, crítica literaria y tradición ancilar latinoamericana EDUARDO BECERRA cuanto a su condición ficcional es la de Los infortunios de Alonso Ramírez, de Carlos Sigüenza y Góngora. Curiosamente, la situación de enunciación del texto de Sigüenza y Góngora se mueve por parámetros muy similares a los de algunos textos testimoniales considerados prototípicos, como sería el caso de Biografía de un cimarrón, de Miguel Barnet, o Me llamo Rigoberta Menchú. En estas obras los testimonios de Esteban Montejo y Rigoberta Menchú están marcados por la labor mediadora de Barnet y Elisabeth Burgos. Sin pretender una identificación total, el papel de Sigüenza y Góngora respecto al testimonio de Alonso Ramírez guarda no pocos paralelismos. Esta doble autoría tiene, en mi opinión, unos efectos muy significativos en el texto, que tienen que ver ( $\sin$ que ello suponga una consideración absolutamente novelesca) con la presencia de una construcción de rango ficcional de mayor grado que la de otros textos coloniales en prosa. Sin entrar en análisis profundos, resulta difícil negar que la reinterpretación, o reconstrucción, por parte del letrado Sigüenza y Góngora de los avatares de Alonso Ramírez provoca la inserción de la peripecia vital del personaje dentro del modelo ficcional canonizado de la picaresca. Frente a esta impresión, si atendemos ahora a la lectura que hace Mabel Moraña de la obra en su artículo «Máscara autobiográfica y conciencia criolla en Infortunios de Alonso Ramírez, de Carlos Sigüenza y Góngora», podemos comprobar todo un ejercicio de deconstrucción de tales presupuestos. Este trabajo se sustenta en el análisis de la función del yo autobiográfico, tratando en todo momento de desligarlo de su posible adscripción picaresca para descubrir implicaciones y significados ideológicos que suponen la constatación de una conciencia social criolla cuestionadora de la ideología imperial. Para demostrarlo, Moraña afirma que el modelo picaresco sólo funciona al comienzo (al abordar los orígenes familiares del personaje, supongo, pues no hace explícitas sus razones), para posteriormente someterse a un proceso de reinvención de tal modelo de carácter deslegitimador. Sin embargo, considero, sin entrar en mayores matizaciones, que el marco general del texto, según el cual el relato de Alonso Ramírez responde a la necesidad de justificar su situación y sus necesidades presentes, constata la presencia del modelo picaresco a lo largo de todo el relato (basta pen- 
sar en el modelo del Lazarillo de Tormes). La negación de este rasgo resulta un paso previo necesario para Mabel Moraña a la hora de demostrar cómo «la utilización del yo tiene en el texto de Sigüenza y Góngora una importancia ideológica que nos remite a la dinámica social novohispana y que apunta a la constitución de lo que puede ya llamarse, a esta altura del siglo XVII, el discurso criollo»; su postulación -continúa más adelante- en función protagónica es la «instancia a partir de la cual la esfera privada se colectiviza, propiciando la socialización de la experiencia individual del personaje»13. Para la autora, el yo de la obra, que parte de una oralidad rastreable en el texto, es un nosotros ideológico, y es en este punto, y en el de la subalternidad de Alonso Ramírez recordada una y otra vez por Moraña en su artículo, donde este planteamiento recuerda a perspectivas de análisis del género testimonial. Como nos recuerda Elzbieta Sklodowska en su excelente estudio Testimonio hispanoamericano. Historia, teoría, poéti$\mathrm{Ca}^{14}$, uno de los lugares comunes de la crítica sobre el testimonio es la insistencia en la representatividad del personaje narrador, sea ésta social, étnica, política o todas a la vez, que con su voz conscientemente supera el cerco individual de la simple autobiografía para convertirse en portavoz de una colectividad. «El testimonio -señala Beverley- es principalmente una manera de dar voz y nombre a un pueblo anónimo» ${ }^{15}$. En el análisis de Moraña, el yo deja de ser una instancia literaria impuesta por la canonización picaresca para conformarse como portavoz de una identidad criolla de rango colectivo, por lo tanto creo que los paralelismos son más que evidentes. Al mismo tiempo, Moraña nos invita a desliteraturizar el texto para descolonizarlo y así convertirlo en expresión de signo identitario ${ }^{16}$.

Lo visto hasta aquí acerca de los nuevos paradigmas de cierta crítica hispanoamericanista, del papel del testimonio en estos cambios y de sus consecuencias para los estudios coloniales, esconde un problema de alcance más general. Salta a la vista que, en buena medida, los postulados de la nueva crítica buscan

la reformulación de la identidad latinoamericana desde nuevos parámetros que insisten en cuestionar el papel demasiado relevante que se le asignó a la literatura en tal proceso. A este respecto señala Beverley en el ya citado artículo de «Post-Literatura»: «El problema [...] es que seguimos sin embargo mirando a la literatura como si fuera el discurso verdaderamente formador de la identidad y posibilidad latinoamericanas [...]. La celebración que propone esta conferencia -señala más adelante- añade una dimensión más a esta postura: la idea no tanto de la literatura, sino de la crítica literaria como el discurso formador de una modernidad latinoamericana» ${ }^{17}$. Aunque luego matice algo este juicio, estas palabras reflejan con exactitud la situación paradójica de este proceso. Asumido el ejercicio crítico como un trabajo descolonizador que busca romper los sólidos muros de la autoridad de la ciudad letrada, el crítico académico (y por lo tanto habitante de esta ciudad con todos sus derechos y privilegios) se arroga ( $`$ en un gesto autoritario?, me pregunto) la capacidad de conformar desde su ámbito los nuevos perfiles de la identidad latinoamericana. Pero hay una cosa más, sorprende también ver cómo en el ámbito de la literatura hispanoamericana del presente discurren en paralelo una literatura que busca obcecadamente desfundamentar el discurso identitario de las décadas pasadas y una crítica que se aferra a esa búsqueda desde nuevas perspectivas que precisamente conllevan el arrinconamiento de lo literario. Para mí, en este punto, la literatura, como así ha ocurrido siempre, se anticipa a la crítica y construye una fisonomía del presente mucho más certera. De ahí que debamos preguntarnos: ¿para qué acabar con ella entonces?

\section{3}

Mabel Moraña, «Máscara autobiográfica y conciencia criolla en Infortunios de Alonso Ramírez, de Carlos Sigüenza y
Góngora», en Viaje al silencio. Exploraciones del discurso barroco, México, UNAM, 1998, págs. 227-230 (págs. 219220).
14

Elzbieta Sklodowska, Testimonio hispanoamericano. Historia, teoría, poética, Peter Lang, Nueva York, 1992.

\section{5}

John Beverley, «Anatomía del testimonio», art. cit., pág. 15.

16

La vinculación de las ideas de Mabel Moraña con los nuevos paradigmas críticos expuestos al comienzo de este trabajo no se sustentan sólo en las coincidencias expuestas sino que surgen desde esos nuevos planteamientos y se han ido haciendo más estrechas con el paso del tiempo. Así, en el año 2000, Moraña fue la editora del libro Nuevas pers pectivas de/sobre América Latina: el desafío de los estudios culturales ( $2^{\mathrm{g}}$ ed., Universidad de Pittsburg, Instituto Internacional de Literatura Iberoamericana). En el prólogo a este volumen, afirma: «Es indudable que los estudios culturales han realizado ya, para el caso de América Latina, una intervención fundamental, quizá definitiva, en la manera de concebir la cultura y las relaciones entre canonicidad y disciplinariedad, tal como éstas eran entendidas hasta la década de los años 70» (pág. 14).

17 John Beverley, art. cit., pág. 389. 